\title{
Ball Milling to Build the Hybrid Mesocrystals of Ibuprofen and Aragonite
}

\author{
Kyoung A Cho, Insil Choi, and Il Won Kim \\ Department of Chemical Engineering, Soongsil University, Seoul 156-743, Republic of Korea \\ Correspondence should be addressed to Il Won Kim; iwkim@ssu.ac.kr
}

Received 4 July 2014; Accepted 3 September 2014

Academic Editor: Xinqing Chen

Copyright (C) 2015 Kyoung A Cho et al. This is an open access article distributed under the Creative Commons Attribution License, which permits unrestricted use, distribution, and reproduction in any medium, provided the original work is properly cited.

\begin{abstract}
Mesocrystal formation is one of the new paradigms of the nonclassical crystallization, where the assembly of crystal domains is observed. Also, it has been recently employed in studies on drug formulation to utilize controlled dissolution of the drug domains. In this report, ibuprofen was attempted to form hybrid mesocrystals with calcium carbonate crystals. Two polymorphs of calcium carbonate (aragonite and calcite) were used during the solid-state process of ball milling. Structural analyses confirmed the mesocrystal formation of ibuprofen with aragonite but not with calcite. The origin of the observed behavior was found from the higher affinity of ibuprofen to aragonite, especially its $\left(\begin{array}{lll}0 & 1 & 0\end{array}\right)$ surface, compared to calcite. The hybrid mesocrystals of ibuprofen and aragonite showed the environment-responsive release behavior, where the stability of aragonite was the controlling factor for the release kinetics of ibuprofen.
\end{abstract}

\section{Introduction}

Mesocrystals are increasingly found as the products of nonclassical crystallization in the diverse fields of materials [1]. The examples are especially abundant in biological and bioinspired crystallization. For example, the nacre of red abalone is constructed as the layers of microcrystals that are also the assembled structures of nanocrystals [2,3]. Similar findings have been seen in the nacre of giant oyster, the spicules of calcareous sponges, and the skeletal structure of sea urchins [4-6] In addition, synthetic mesocrystals inspired by biomineralization have been reported in the solution crystallization, where the crystal assembly was through interparticle interactions and/or heterogeneous nucleation [7-10].

Controlled release has attracted great interest in the pharmaceutical research. The basic notion is to maintain the drug concentration in blood above the effective level and below the safe concentration for a sustained period of time, and many efforts have been made at the same time to develop environment-responsive systems that satisfy the specific needs of the drugs [11]. Mesocrystals have been also explored in this regard to control the dissolution rate of the active pharmaceutical ingredients (APIs). For example, the sustained release of carbamazepine and adefovir dipivoxil was associated with their mesocrystal formation induced by polymeric additives $[12,13]$; the enhanced release of ibuprofen was found for its mesocrystals formed with sodium dodecyl sulfate [14].

Mechanical milling was utilized to prepare hybrid structures of APIs with inorganic materials, such as silica, magnesium aluminosilicate, aluminum silicate, and aluminum hydroxide, to alter the physicochemical properties of the APIs [15-18]. It has been also extensively explored in recent years to prepare cocrystals and solvates/hydrates of APIs, and the solid-state process without or minimal use of solvents makes it attractive as a greener process than conventional procedures [19-22].

In the present study, we have attempted a simple method of ball milling to prepare hybrid mesocrystals of ibuprofen (IBU) and calcium carbonate. We explored two anhydrous polymorphs of calcium carbonate (calcite and aragonite) since the distinctive molecular arrangements of the active surfaces could contribute to the different interactions with IBU. Also, the $\mathrm{pH}$-responsive dissolution behaviors of the mesocrystals were expected because of the high and sparing solubility of calcium carbonate at low and neutral $\mathrm{pH}$, respectively [23]. 


\section{Materials and Methods}

2.1. Preparation of Calcite and Aragonite. Two polymorphs of anhydrous calcium carbonate were prepared following a method using water-alcohol mixtures [24]. To obtain calcite, sodium carbonate ( $26.0 \mathrm{mmol}, 2.75 \mathrm{~g}: \mathrm{Na}_{2} \mathrm{CO}_{3}: \geq 99.0 \%$, Sigma-Aldrich, Milwaukee, WI, USA) was completely dissolved in the solution of $100 \mathrm{~mL}$ ethanol (HPLC grade, $99.0 \%$, Samchun, Pyeongtaek, South Korea) and $900 \mathrm{~mL}$ deionized water (DI water: resistivity of $18.2 \mathrm{MOhm} \cdot \mathrm{cm}$, Direct-Q from Millipore, Billerica, MA, USA) contained in a $1000 \mathrm{~mL}$ volumetric flask at room temperature (ca. $25^{\circ} \mathrm{C}$ ), and then calcium chloride (26.0 mmol, $2.89 \mathrm{~g}: \mathrm{CaCl}_{2}: 99+\%$, SigmaAldrich, Milwaukee, WI, USA) was added to the solution. The solution was vigorously mixed at all time with a stir bar (length, $30 \mathrm{~mm}$ ) equipped with a magnetic stirrer (HS180, Misung Scientific Co., Seoul, South Korea). The procedure to obtain aragonite was the same as that for calcite except that $50 \mathrm{vol} \%$ ethanol $(500 \mathrm{~mL}$ ethanol and $500 \mathrm{~mL}$ DI water) was used. After $24 \mathrm{~h}$, the precipitated products were collected by vacuum filtration (number 20 filter paper, pore diameter $5 \mu \mathrm{m}$, Hyundai Micro, Seoul, South Korea), washed with DI water, and dried in a convection oven at $40^{\circ} \mathrm{C}$ for $12 \mathrm{~h}$ before further use.

2.2. Ball Milling IBU with Calcite and Aragonite. Ibuprofen (IBU: >98\%) was used as obtained from Sigma-Aldrich (Milwaukee, WI, USA). IBU (100 mg) was ball-milled with calcite or aragonite $(100 \mathrm{mg})$ at the frequency of $10 \mathrm{~Hz}$, and the milling time was 120 or $240 \mathrm{~min}$. For the procedure, a Retsch ball mill (MM 200, Haan, Germany) was used with a cylindrical stainless steel jar (about $25 \mathrm{~mL}$; inner diameter ca. $26 \mathrm{~mm}$ and inner length ca. $52 \mathrm{~mm}$ ) and two stainless steel balls (diameter, $9 \mathrm{~mm}$ ), which was often utilized in pharmaceutical grinding [20]. The ball-milled products were immediately used for further characterization.

2.3. Characterization of Raw and Ball-Milled Materials. Morphologies of IBU, calcite, aragonite, and ball-milled products were characterized using field-emission scanning electron microscopy (FE-SEM: JSM-6700F, JEOL, Tokyo, Japan) after thin $\mathrm{Au}$ coating (Cressington Sputter Coater 108, Watford, UK) to minimize surface charging. The materials were also characterized in their crystal structures using powder Xray diffraction (XRD: D2 PHASER, Bruker AXS, Billerica, MA, USA). XRD was performed with $\mathrm{CuK} \alpha$ radiation $(\lambda=$ $1.5406 \AA$ at $30 \mathrm{kV}, 10 \mathrm{~mA}$ ) in the $2 \theta$ range of $5-40^{\circ}$ (scanning rate, $1^{\circ} / \mathrm{min}$ ). Fourier transformation infrared spectroscopy (FT-IR) was performed using a Cary 660 FTIR Spectrometer (Agilent Technologies, Santa Clara, CA, USA). KBr (FT-IR grade, $\geq 99 \%$, Sigma-Aldrich, Milwaukee, WI, USA) discs were prepared for the transmission mode, where the IR spectra were collected in the wavenumber range of 4000$400 \mathrm{~cm}^{-1}$.

Thermal analyses were performed via differential scanning calorimetry (DSC: DSC 821e, Mettler-Toledo, Columbus, OH, USA) and thermogravimetric analysis (TGA: TGA/SDTA 851e, Mettler-Toledo). DSC was to check the crystalline state of IBU, and it was precalibrated for enthalpy and temperature using indium. The scanning for the IBU containing samples $(2-3 \mathrm{mg}$ each in a hermetically sealed aluminum crucible) was from 25 to $100^{\circ} \mathrm{C}$ with a heating rate of $10^{\circ} \mathrm{C} / \mathrm{min}$, and DSC experiments were repeated in triplicate for each sample. TGA was performed from 25 to $900^{\circ} \mathrm{C}$ with a scanning rate of $10^{\circ} \mathrm{C} / \mathrm{min}(10-15 \mathrm{mg}$ each in an open alumina crucible). Both DSC and TGA were under nitrogen environment.

Release behaviors of IBU were studied at $\mathrm{pH} 1.2$ (corresponding to the gastric fluid) and 6.8 (corresponding to the intestinal fluid) using buffer solutions of $\mathrm{HCl}-\mathrm{KCl}$ and phosphate, respectively $[25,26]$. Powders containing IBU (5 mg for IBU only; $10 \mathrm{mg}$ for ball-milled samples of IBU and calcium carbonate) were placed in a $300 \mathrm{~mL}$ solution ( $500 \mathrm{~mL}$ round bottom flask) at $37^{\circ} \mathrm{C}$, and the mixture was stirred at $200 \mathrm{rpm}$ using an overhead stirrer (HS-30D, Wisd Laboratory Instruments, Wertheim, Germany). To analyze the concentration of IBU in the solution, $3 \mathrm{~mL}$ samples were removed after 5, 10, 20,30,60, 120, and $180 \mathrm{~min}$, and the solution was refilled immediately with the original buffer solutions to keep the volume of the solution constant. The solution sample removed at a given interval was filtered through a cellulose acetate filter (pore size $0.45 \mu \mathrm{m}$, MFS13, Advantec, Tokyo, Japan), and its UV absorbance was measured at $222 \mathrm{~nm}$ (Optizen POP, Mecasys, Daejeon, South Korea) where the absorbance was at its maximum. The UV absorbance was then converted to the concentration using a preconstructed calibration curve. The release experiments were independently repeated in triplicate for each sample.

2.4. Computational Calculations of Binding Energy. The binding energy of IBU on the surfaces of aragonite and calcite was calculated using the Materials Studio simulation software (version 7.0) from Accelrys (San Diego, CA, USA) equipped with Forcite module and COMPASS force field [27], which was known for being effective for the calculations of the binding on calcium carbonate [28]. The $\left(\begin{array}{lll}0 & 1 & 0\end{array}\right) /\left(\begin{array}{lll}1 & 1 & 0\end{array}\right)$ faces of aragonite and the (l $\left.\begin{array}{lll}1 & 0 & 4\end{array}\right)$ of calcite were selected as the adsorption surfaces based on the previous morphological observations [10, 24, 29]. Electrostatic energy terms were treated using Ewald summation method, and van der Waals energy was calculated with a cutoff distance of $12.5 \AA$ using an atom-based summation method. The crystal structures of aragonite and calcite were obtained from the previous publications [30, 31], and the partial charge was force-field assigned. The initial geometry optimization and the charge assignment of IBU were also performed before adsorption simulation. The adsorption surfaces of calcium carbonate crystals were cleaved with thickness of $17 \AA$, which were then expanded over $40 \AA \times 40 \AA$. The centers of geometry of calcium and carbonate were considered for them to be included in the cleaved slab. After placing the IBU molecule at the center of the surfaces, Forcite quench (5 ps with $1 \mathrm{fs}$ step) was performed to find the structure of the minimum energy. The NVT ensemble (Nosé thermostat) was used at $303 \mathrm{~K}$ reflecting the measured temperature during the ball milling process [32]. Among the 5,000 different structures, the structures at every 500 frames were quenched and optimized. The binding energy $\left(E_{b}\right)$ was calculated for 


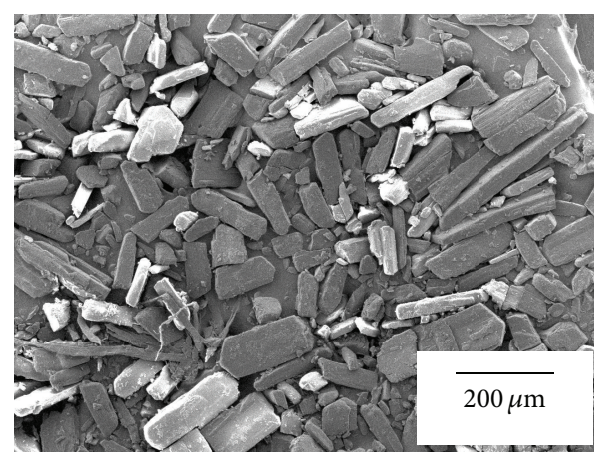

(a)

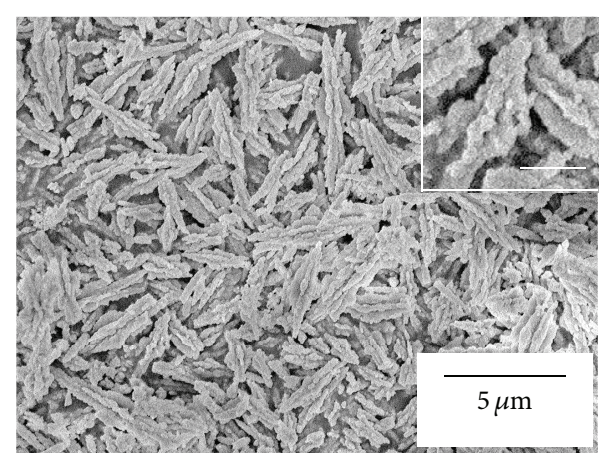

(b)

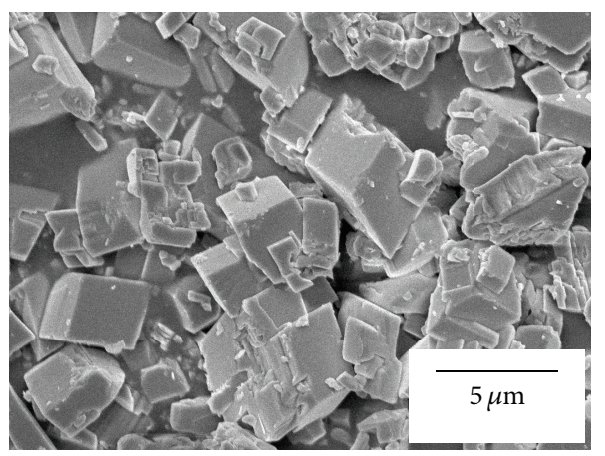

(c)

FigurE 1: SEM images of ibuprofen (a), aragonite (b), and calcite (c) crystals. The scale bar of the inset of (b) is $1 \mu \mathrm{m}$.

the minimum energy structure of each surface: $E_{b}=E_{t}-$ $\left(E_{i}+E_{s}\right)$, where $E_{t}, E_{i}$, and $E_{s}$ are the total energy, the energy of adsorbed IBU, and the energy of surface, respectively.

\section{Results and Discussion}

3.1. Structures of Ball-Milled IBU with Calcite and Aragonite. The IBU crystals before milling as well as synthesized polymorphs of calcium carbonate (calcite and aragonite) were shown in Figure 1. The IBU crystals were plate-shaped with their length of about $100-200 \mu \mathrm{m}$ (Figure 1(a)). They were of typical morphology as previously observed: the large $\left\{\begin{array}{lll}1 & 0 & 0\end{array}\right\}$ faces and the $\left\{\begin{array}{lll}0 & 0 & 1\end{array}\right\},\left\{\begin{array}{lll}1 & 1 & 0\end{array}\right\}$ side faces $[33,34]$. The crystal shapes of the synthesized polymorphs of calcium carbonate were also of routinely observed morphology. The aragonite crystals were needle-shaped with their length of about $2-5 \mu \mathrm{m}$ (Figure 1(b)). As shown in the inset, the aragonite needle was composed of submicron domains, and this observation was in agreement with the previous study using the same synthesis method [24]. The utilized method is known to generate $\left\{\begin{array}{lll}1 & 1 & 0\end{array}\right\}$ and $\left\{\begin{array}{lll}0 & 1 & 0\end{array}\right\}$ faces of aragonite as the enclosing surfaces, and the $\left\{\begin{array}{lll}0 & 1 & 0\end{array}\right\}$ is also the distinct cleavage plane $[24,29]$. The calcite crystals were rhombohedral with most of their size at $1-5 \mu \mathrm{m}$ (Figure $1(\mathrm{c})$ ). The enclosing surfaces of the rhombs are known as the $\left\{\begin{array}{lll}1 & 0 & 4\end{array}\right\}$ faces, which are also the perfect cleavage planes [10, 29, 35].

When IBU was ball-milled with the crystals of calcium carbonate, significant differences were observed between the cases with aragonite and calcite. When IBU was ballmilled with aragonite, the aragonite needles were mostly disassembled into their individual submicron domains (Figures 2(a) and 2(b)), although some needle-shaped parts could be found (arrowheads of Figures 2(a) and 2(b)). More importantly, IBU and aragonite formed tightly integrated mesocrystal structures of the overall size about 4-10 $\mu \mathrm{m}$. (In the case of IBU/aragonite milling, the microscopic examination did not reveal clear differences between the 120- and 240-minute samples.) In contrast, IBU ball milled with calcite did not show mesocrystal formation. IBU and calcite mostly remained as separate entities, although a small part of them appeared associated as indicated by the arrowheads of Figures 2(c) and 2(d). Note that calcite was easily distinguishable because of its $\left\{\begin{array}{lll}1 & 0 & 4\end{array}\right\}$ cleavage surfaces. (In the case of IBU/calcite, the calcite appeared more fractured and smaller after the 240-minute milling than after $120 \mathrm{~min}$.)

XRD analysis confirmed the nearly exclusive formation of calcite and aragonite during the preparation step (Figure 3). The prominent diffraction peaks of aragonite were shown at ca. $26.0,27.0,35.9$, and $38.2^{\circ}$ for the $\left\{\begin{array}{lll}1 & 1 & 1\end{array}\right\},\left\{\begin{array}{lll}0 & 2 & 1\end{array}\right\}$, $\left\{\begin{array}{lll}2 & 0 & 0\end{array}\right\}$, and $\left\{\begin{array}{lll}1 & 3 & 0\end{array}\right\}$ planes, respectively (Figure 3(a)) [36]. Those of calcite were at ca. 22.6, 29.0, 35.6, and $39.0^{\circ}$ for the $\left\{\begin{array}{lll}0 & 1 & 2\end{array}\right\},\left\{\begin{array}{lll}1 & 0 & 4\end{array}\right\},\left\{\begin{array}{lll}1 & 1 & 0\end{array}\right\}$, and $\left\{\begin{array}{lll}1 & 1 & 3\end{array}\right\}$ planes, respectively (Figure 3(b)) [36]. (Note that the calcite $\left\{\begin{array}{lll}1 & 0 & 4\end{array}\right\}$ peak existed in negligible intensity in the aragonite batch.) The polymorphs of aragonite and calcite were also distinguishable using FT-IR analysis (Figure 4). The former had characteristic doublet peaks at 700 and $713 \mathrm{~cm}^{-1}$ as well as peaks at 1082 and $1786 \mathrm{~cm}^{-1}$ (Figures 4(a) and 4(b)), whereas the latter had a singlet at $711 \mathrm{~cm}^{-1}$, nothing around $1080 \mathrm{~cm}^{-1}$, and a peaks at $1799 \mathrm{~cm}^{-1}$ (Figures 4(c) and 4(d)) [37-39]. 


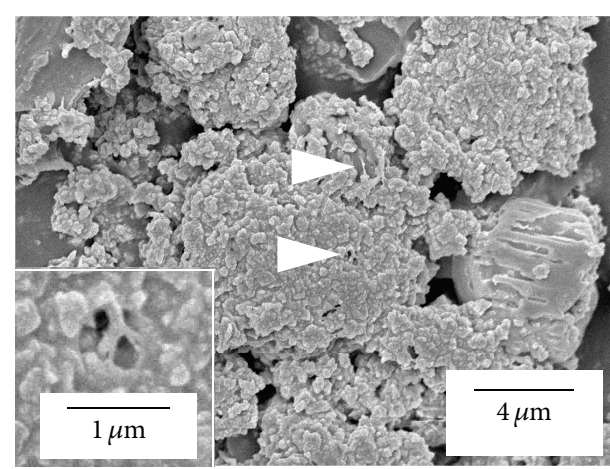

(a)

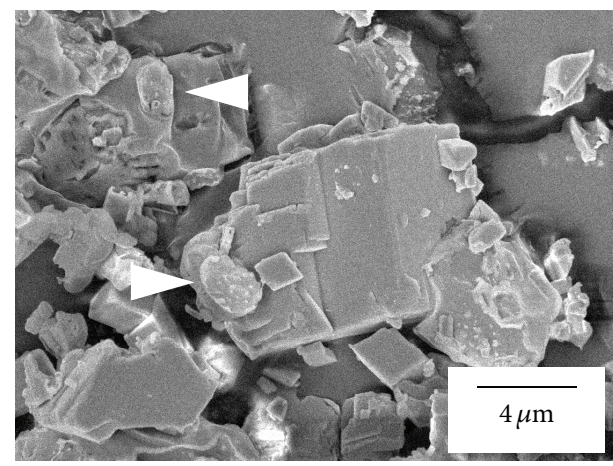

(c)

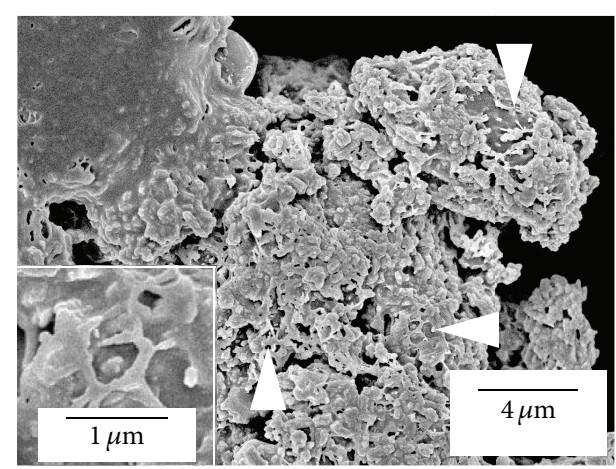

(b)

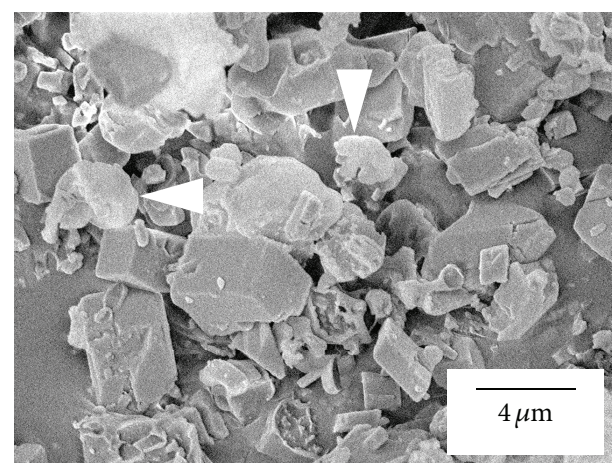

(d)

FIGURE 2: SEM images of IBU/aragonite after ball milling for (a) 120 and (b) $240 \mathrm{~min}$; IBU/calcite after ball milling for (c) 120 and (d) 240 min. Arrowheads of (a) and (b) indicated the aragonite needles, and those of (c) and (d) indicated IBU. Also shown in the insets of (a) and (b) were the submicron domains as well as the needles of aragonite integrated with IBU.

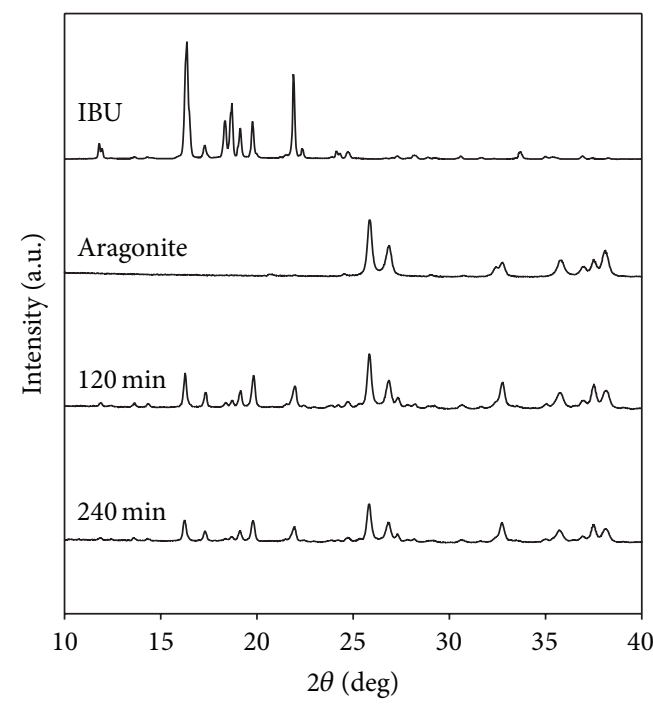

(a)

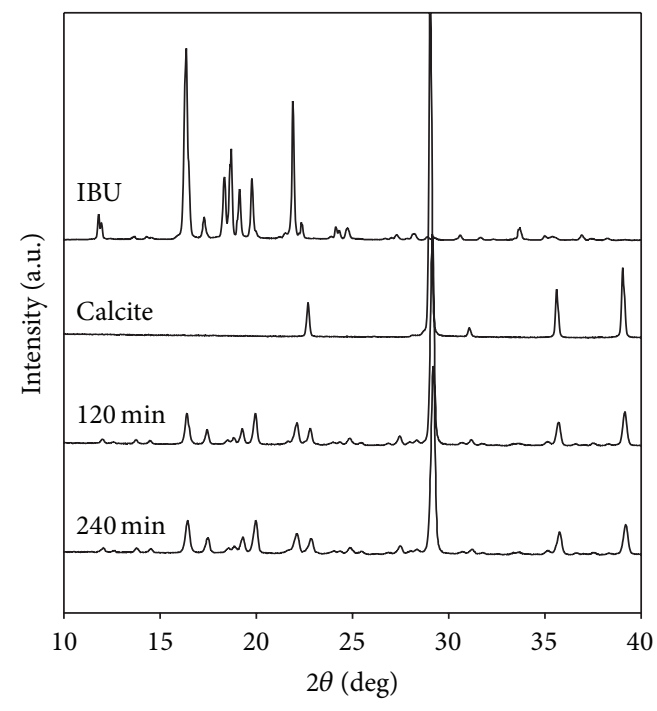

(b)

FIGURE 3: XRD patterns of IBU/aragonite (a) and IBU/calcite (b) before and after ball milling.

Ball milling did not alter the structures of IBU crystals significantly enough to generate new XRD diffraction peaks from different crystal structures (Figure 3). Major XRD diffraction peaks of IBU were at ca. $16.4,18.7,19.8$, and $21.9^{\circ}$ for $\left\{\begin{array}{lll}2 & 1 & 0\end{array}\right\},\left\{\begin{array}{lll}2 & 0 & -2\end{array}\right\},\left\{\begin{array}{lll}0 & 1 & 2\end{array}\right\}$, and $\left\{\begin{array}{lll}2 & 0 & 2\end{array}\right\}$, respectively [40]. All major diffraction peaks were the same after ball milling, although some alterations in the intensity, most noticeably the increased relative intensity of $\left\{\begin{array}{lll}0 & 1 & 2\end{array}\right\}$ peak at ca. $19.8^{\circ}$, 


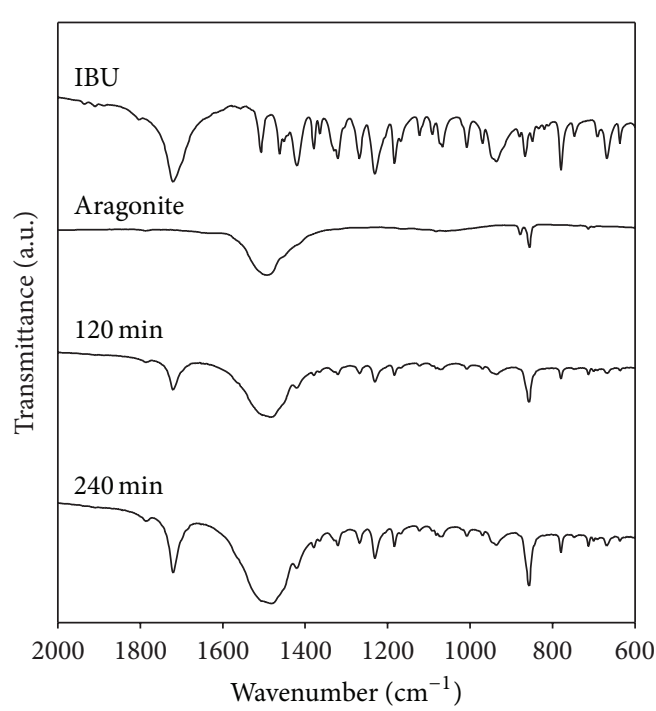

(a)

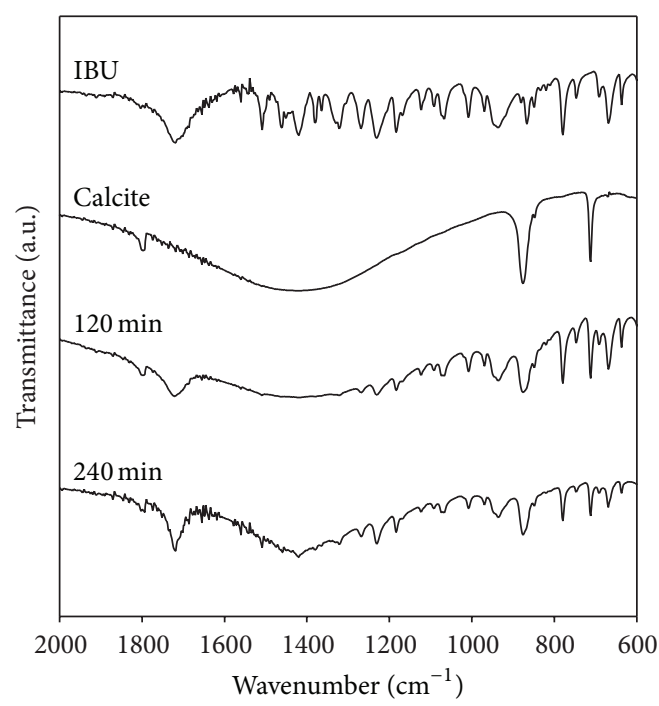

(c)

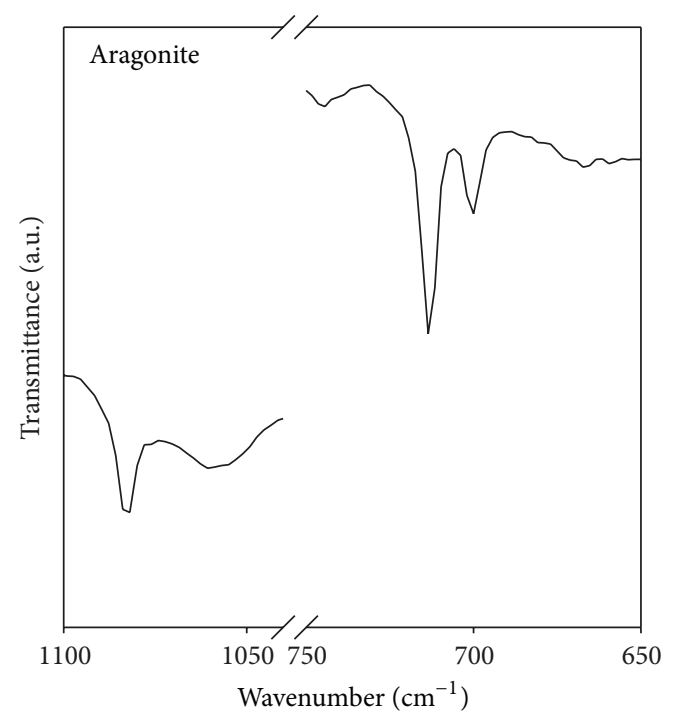

(b)

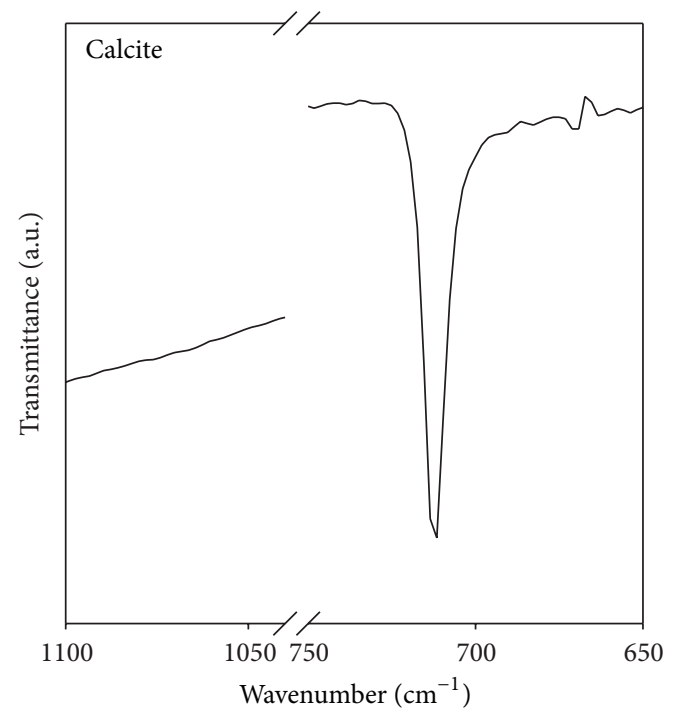

(d)

FIGURE 4: IR spectra of IBU/aragonite before and after ball milling (a); aragonite (zoomed in between 1100 and $650 \mathrm{~cm}^{-1}$ ) $(\mathrm{b})$; IBU/calcite before and after ball milling (c); calcite (zoomed in between 1100 and $\left.650 \mathrm{~cm}^{-1}\right)(\mathrm{d})$.

indicated the changes in the crystal morphology. In addition, the analysis of the full width at half maximum (FWHM) was in agreement with the microscopic observation. The FWHM was analyzed based on the relatively intensified $\left\{\begin{array}{lll}0 & 1 & 2\end{array}\right\}$ peak. The FWHM was about $0.11^{\circ}$ before milling, and it increased after milling with aragonite or calcite. The FWHM values were 0.16 and $0.17^{\circ}$ after 120 and 240 min of milling with aragonite, respectively. They were 0.17 and $0.19^{\circ}$ after 120 and 240 min with calcite, respectively. Since FWHM is inversely proportional to the crystallite size, the analysis indicated the size decrease of the IBU crystallite with ball milling [41]. Note that the $\left\{\begin{array}{lll}0 & 1 & 2\end{array}\right\}$ plane is parallel to the $a$-axis, which is also perpendicular to the large $\left\{\begin{array}{lll}1 & 0 & 0\end{array}\right\}$ face of the plateshaped IBU crystals before milling (Figure 1(a)) [33, 34]. This suggested that breakage occurred in the perpendicular direction of the large face as would be expected from the original shape of the crystals.

The interactions between IBU and calcium carbonate were further examined with FT-IR and molecular dynamics. FT-IR showed that one of the carbonate-related peaks of aragonite noticeably changed after milling with IBU (Figure 4(a)). The frequency corresponding to asymmetric stretching was at $1495 \mathrm{~cm}^{-1}$ [37], and it became 1485 and $1481 \mathrm{~cm}^{-1}$ after 120 and 240 min of milling with IBU, respectively. In contrast, the corresponding change appeared absent for calcite (Figure 4(b)). Also, note that the change on the IBU side, including that for the carbonyl peak at $1720 \mathrm{~cm}^{-1}$, was difficult to find.

The fundamental aspects of IBU interaction with aragonite and calcite were investigated by studying the binding 


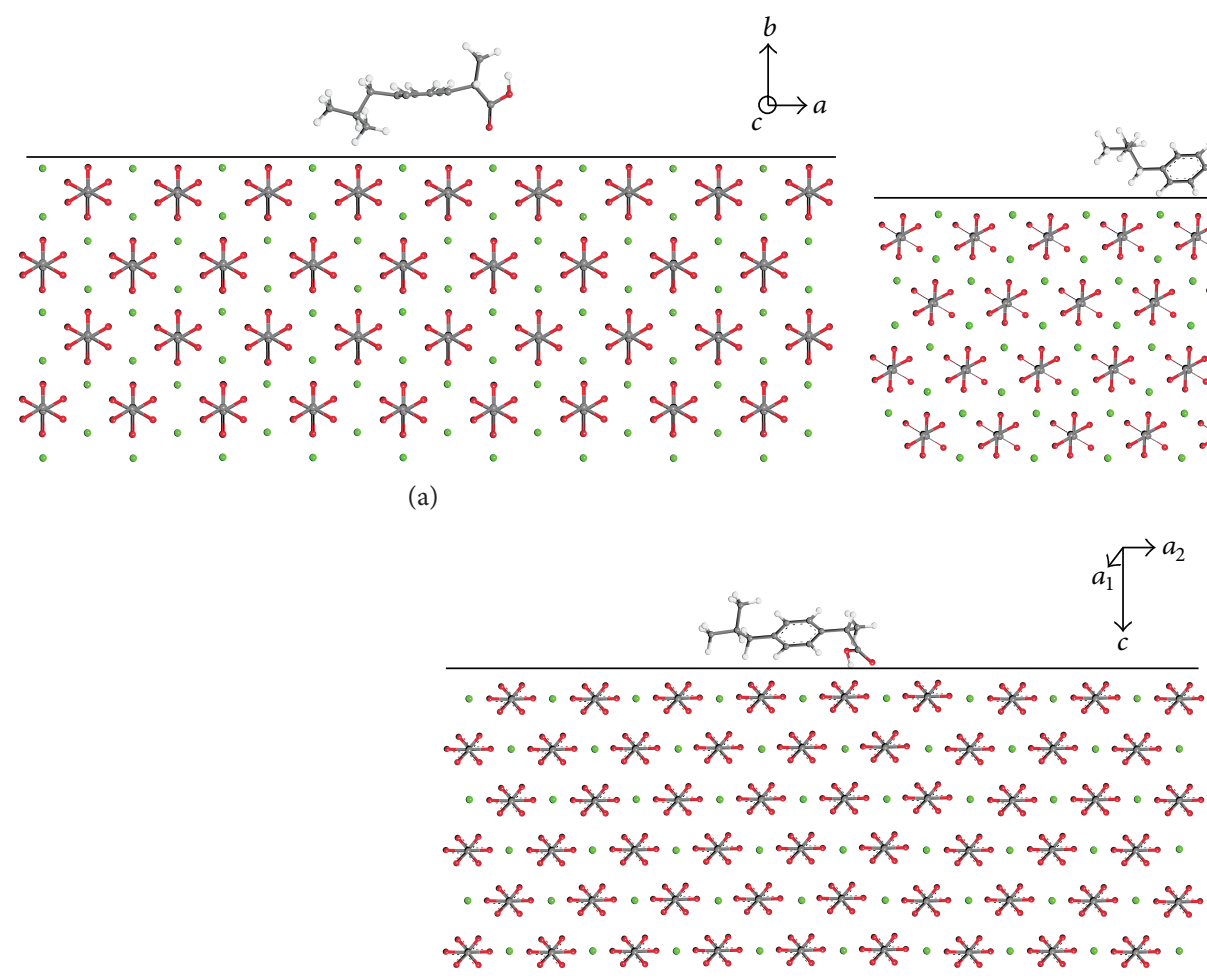

(c)

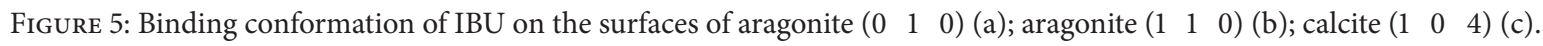

energy and structures. The binding energy of IBU on the mineral surfaces was in the following order: aragonite $\left(\begin{array}{lll}0 & 1 & 0\end{array}\right)$, $|-212 \mathrm{kcal} / \mathrm{mol}| \gg$ aragonite $\left(\begin{array}{lll}1 & 1 & 0\end{array}\right),|-63 \mathrm{kcal} / \mathrm{mol}|>$ calcite (1 0 4 4 , , $|-44 \mathrm{kcal} / \mathrm{mol}|$, and the binding was predominantly of electrostatic nature in all cases. The corresponding binding conformations of IBU to the surfaces were shown in Figure 5. The binding differences seemed to originate from the dissimilar atomic arrangements of the surfaces. Each calcium ion of aragonite and calcite in bulk was coordinated with nine and six oxygens, respectively; the surface calcium of $\left(\begin{array}{lll}0 & 1 & 0\end{array}\right)$ and (1 110$)$ lacked three coordinating oxygens out of nine, whereas that of $\left(\begin{array}{lll}1 & 0 & 4\end{array}\right)$ was short of only one oxygen out of six. This appeared to allow stronger electrostatic interactions of surface calcium of aragonite with the oxygens of IBU. In addition, the subtle differences in the two-dimensional periodic structures between $\left(\begin{array}{lll}0 & 1 & 0\end{array}\right)\{4.961 \AA \times 5.740 \AA\}$ and $\left(\begin{array}{lll}1 & 1 & 0\end{array}\right)\{4.694 \AA \times 5.740 \AA\}$ appeared to contribute to the differences of the IBU binding conformations and interactions.

Overall, the IR analysis and the computational study of the binding indicated the higher affinity of IBU to aragonite compared to calcite. This was consistent with the microscopic observation, where the intimate association of IBU was found with aragonite but not with calcite.

3.2. Properties of Ball-Milled IBU with Calcite and Aragonite. Thermal properties of IBU ball milled with calcium carbonate were examined with DSC. The melting point of IBU was about $77^{\circ} \mathrm{C}$ before milling. It became about 74 and $73^{\circ} \mathrm{C}$ after 120 and $240 \mathrm{~min}$ of milling with aragonite; it was about
76 and $75^{\circ} \mathrm{C}$ after 120 and 240 min of milling with calcite (Figure 6(a)). The melting enthalpy showed greater changes (Figure 6(b)). The reported enthalpy was the normalized value based on the TGA analysis, which revealed the exact amount of IBU in the hybrid sample. (Calcium carbonate, both aragonite and calcite, started to experience weight loss at around $600^{\circ} \mathrm{C}$ to eventually leave ca. $56 \%$ of the original weight. This corresponded to the formation of calcium oxide by losing carbon dioxide; IBU decomposed nearly completely below $300^{\circ} \mathrm{C}$ to leave less than $1 \%$ of the original weight.) The melting enthalpy of IBU was about $172 \mathrm{~J} / \mathrm{g}$ before milling. It became about 162 and $126 \mathrm{~J} / \mathrm{g}$ after 120 and $240 \mathrm{~min}$ of milling with aragonite; it was about 173 and $151 \mathrm{~J} / \mathrm{g}$ after 120 and 240 min of milling with calcite. Overall, the decrease of melting point and enthalpy of IBU was observed after milling, which was probably due to the decrease of the crystal size and crystallinity [42, 43]. Also, the effect of aragonite was more significant than that of calcite, which was in accordance with the structural analysis in the previous section.

Release behaviors of IBU from the ball-milled IBU/ aragonite and IBU/calcite were studied at $\mathrm{pH} 1.2$ and 6.8 (Figure 7), where the change of $\mathrm{pH}$ during the release was less than 0.1 in all cases. The release behavior from the IBU/aragonite hybrid was $\mathrm{pH}$ responsive. After milling for $240 \mathrm{~min}$, the initial release $(<30 \mathrm{~min})$ accelerated at $\mathrm{pH} 1.2$, while it decelerated at $\mathrm{pH}$ 6.8, compared with neat IBU. This was apparently due to the high solubility of aragonite at low $\mathrm{pH}$ [23], combined with its intimate association with IBU. Note that 120-minute milling was not as effective at $\mathrm{pH} 1.2$, while its deceleration effect at $\mathrm{pH} 6.8$ was valid. In 


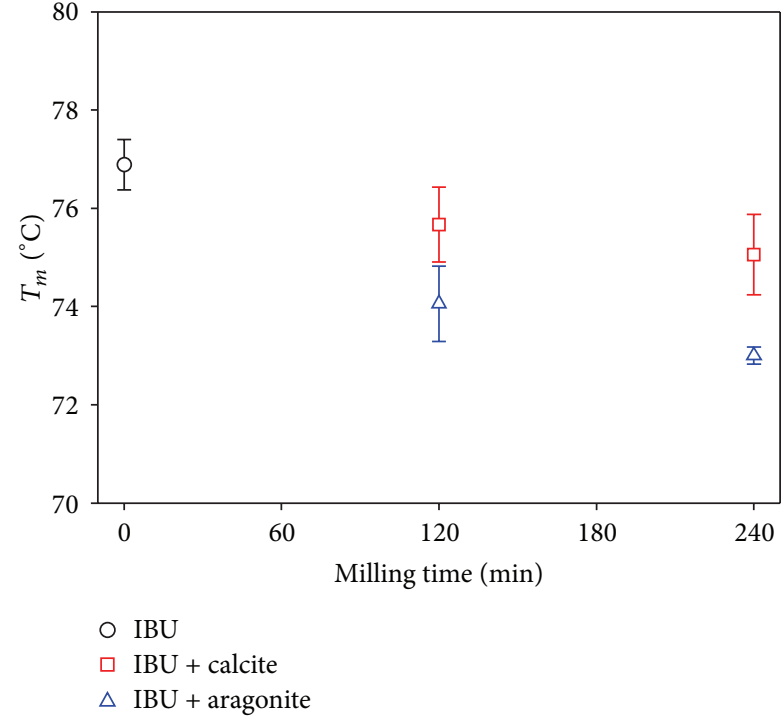

(a)

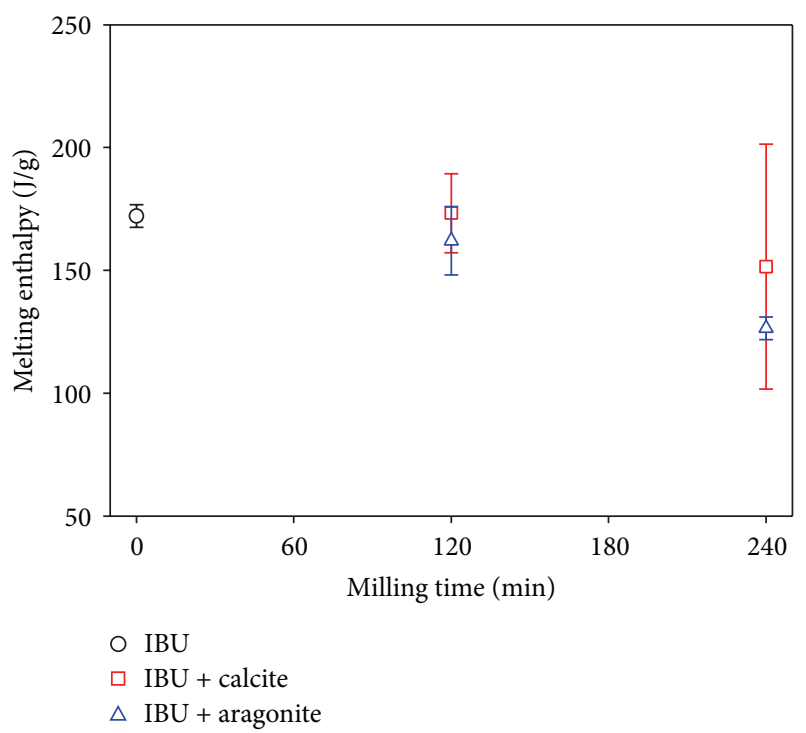

(b)

FIGURE 6: (a) Melting points and (b) melting enthalpy of IBU/aragonite and IBU/calcite after ball milling.
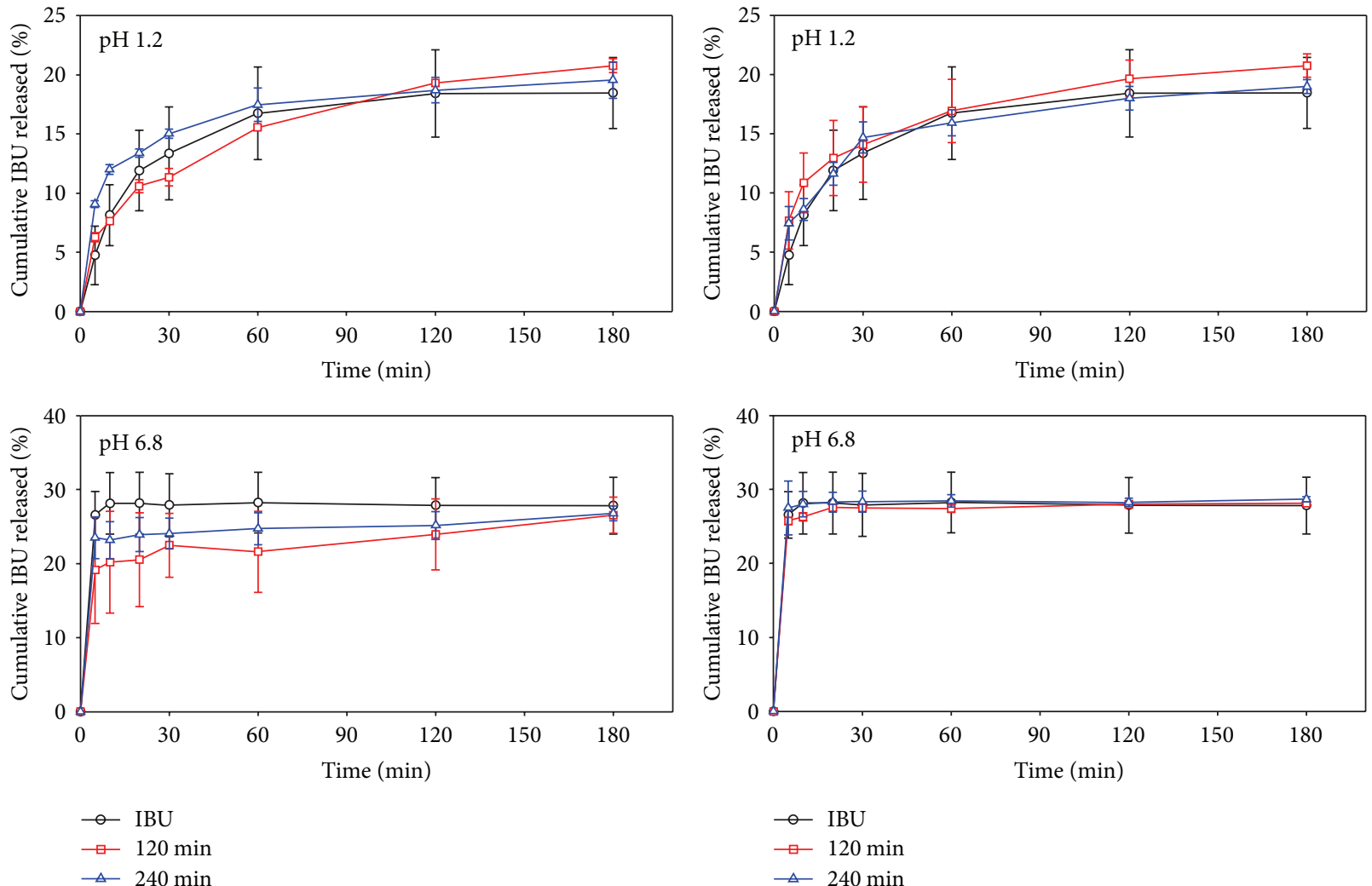

(a)

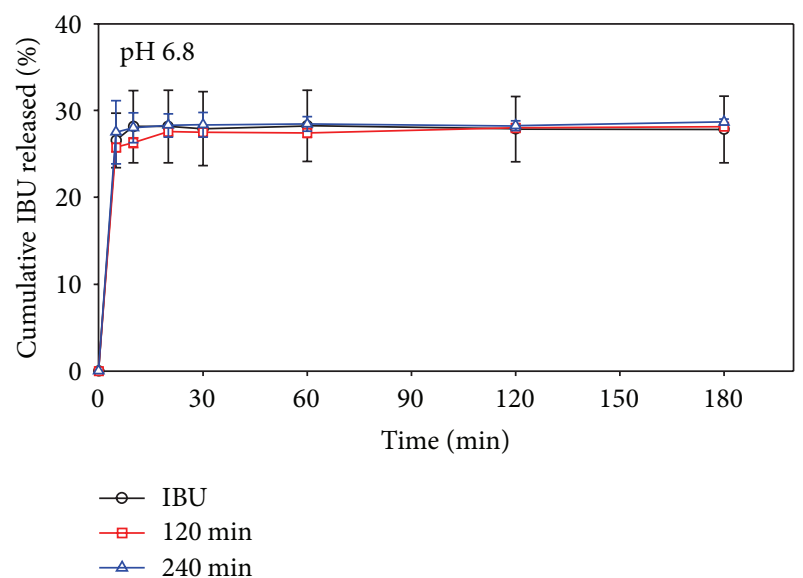

(b)

FIGURE 7: IBU release profiles at $\mathrm{pH} 1.2$ and 6.8 from ball-milled IBU/aragonite (a) and IBU/calcite (b).

contrast, ball milling of IBU with calcite was not effective in modulating the release rate. Overall, the release behaviors of IBU confirmed that they could be adjusted only when IBU was intimately associated with the ball-milled substrate.
When the substrate was rapidly soluble, the IBU release was expedited; when the substrate was marginally soluble, the release slowed down. Further studies on the quantitative analysis of the release kinetics and on the extended release 
behavior with the fine-tuned structures would be necessary to establish the utility of the mesocrystals in the controlled drug release.

\section{Conclusions}

In summary, two anhydrous polymorphs of calcium carbonate (aragonite and calcite) were employed during ball milling of IBU to generate IBU/calcium carbonate hybrid materials. Aragonite polymorph was intimately integrated with IBU to form a mesocrystal-like structure, whereas calcite did not seem to be as effective under the experimental conditions employed in the present study. Aragonite and IBU kept their original crystal structures within the mesocrystals, although morphological variations occurred. Aragonite/IBU interaction was verified by the changes in the IR vibration of the carbonate of aragonite, and its strong nature was corroborated by the binding energy computationally obtained. The IBU fused with aragonite showed modulated thermal behavior, further confirming the observed structures. Finally, the IBU release behavior could be regulated through the conditions affecting the aragonite substrate. The IBU release sped up under the conditions disintegrating aragonite, and it slowed down when aragonite was stable. The present study indicates that the substrates that disintegrate at specific conditions can be utilized for the environment-responsive release of APIs. For this purpose, it also appears that the substrates need to form intimately associated structures with APIs to be delivered.

\section{Conflict of Interests}

The authors declare that there is no conflict of interests regarding the publication of this paper.

\section{Acknowledgments}

This research was supported by Basic Science Research Program through the National Research Foundation of Korea (NRF) funded by the Ministry of Education (NRF2013R1A1A2012036).

\section{References}

[1] H. Cölfen and M. Antonietti, Mesocrystals and Nonclassical Crystallization, John Wiley \& Sons, Chichester, UK, 2008.

[2] X. Li, W.-C. Chang, Y. J. Chao, R. Wang, and M. Chang, "Nanoscale structural and mechanical characterization of a natural nanocomposite material: The shell of red abalone," Nano Letters, vol. 4, no. 4, pp. 613-617, 2004.

[3] L. Addadi, D. Joester, F. Nudelman, and S. Weiner, "Mollusk shell formation: a source of new concepts for understanding biomineralization processes," Chemistry-A European Journal, vol. 12, no. 4, pp. 980-987, 2006.

[4] M. Rousseau, E. Lopez, P. Stempflé et al., "Multiscale structure of sheet nacre," Biomaterials, vol. 26, no. 31, pp. 6254-6262, 2005.

[5] I. Sethmann, R. Hinrichs, G. Wörheide, and A. Putnis, "Nanocluster composite structure of calcitic sponge spicules-a case study of basic characteristics of biominerals," Journal of Inorganic Biochemistry, vol. 100, no. 1, pp. 88-96, 2006.
[6] Y. Oaki and H. Imai, "Nanoengineering in echinoderms: the emergence of morphology from nanobricks," Small, vol. 2, no. 1, pp. 66-70, 2006.

[7] O. Grassmann, G. Müller, and P. Löbmann, "Organic-inorganic hybrid structure of calcite crystalline assemblies grown in a gelatin hydrogel matrix: relevance to biomineralization," Chemistry of Materials, vol. 14, no. 11, pp. 4530-4535, 2002.

[8] H. Cölfen and M. Antonietti, "Mesocrystals: inorganic superstructures made by highly parallel crystallization and controlled alignment," Angewandte Chemie International Edition, vol. 44, no. 35, pp. 5576-5591, 2005.

[9] R. Kim, C. Kim, S. Lee, J. Kim, and I. W. Kim, "In situ atomic force microscopy study on the crystallization of calcium carbonate modulated by poly(vinyl alcohol)s," Crystal Growth \& Design, vol. 9, no. 11, pp. 4584-4587, 2009.

[10] I. W. Kim, S. Collino, and J. S. Evans, "Cooperative modulation of mineral growth by prismatic-associated Asprich sequences and $\mathrm{Mg}(\mathrm{II})$," International Journal of Molecular Sciences, vol. 13, no. 3, pp. 3949-3958, 2012.

[11] K. Park, "Controlled drug delivery systems: past forward and future back," Journal of Controlled Release, vol. 190, pp. 3-8, 2014.

[12] I. Katzhendler, R. Azoury, and M. Friedman, "Crystalline properties of carbamazepine in sustained release hydrophilic matrix tablets based on hydroxypropyl methylcellulose," Journal of Controlled Release, vol. 54, no. 1, pp. 69-85, 1998.

[13] M. K. Lee, H. Lee, I. W. Kim, and J. Lee, "Novel polymorphic form of adefovir dipivoxil derived from polymer-directed crystallization," Pharmazie, vol. 66, no. 10, pp. 766-770, 2011.

[14] T. Lee and C. W. Zhang, "Dissolution enhancement by bioinspired mesocrystals: the study of racemic $(R, S)-( \pm)$-sodium ibuprofen dihydrate," Pharmaceutical Research, vol. 25, no. 7, pp. 1563-1571, 2008.

[15] T. Watanabe, S. Hasegawa, N. Wakiyama, A. Kusai, and M. Senna, "Prediction of apparent equilibrium solubility of indomethacin compounded with silica by ${ }^{13} \mathrm{C}$ solid state NMR," International Journal of Pharmaceutics, vol. 248, no. 1-2, pp. 123129, 2002.

[16] M. K. Gupta, A. Vanwert, and R. H. Bogner, "Formation of physically stable amorphous drugs by milling with neusilin," Journal of Pharmaceutical Sciences, vol. 92, no. 3, pp. 536-551, 2003.

[17] S. Mallick, S. Pattnaik, K. Swain et al., "Formation of physically stable amorphous phase of ibuprofen by solid state milling with kaolin," European Journal of Pharmaceutics and Biopharmaceutics, vol. 68, no. 2, pp. 346-351, 2008.

[18] S. Mallick, S. Pattnaik, K. Swain et al., "Physicochemical characterization of interaction of ibuprofen by solid-state milling with aluminum hydroxide," Drug Development and Industrial Pharmacy, vol. 34, no. 7, pp. 726-734, 2008.

[19] W. Jones, W. D. S. Motherwell, and A. V. Trask, "Pharmaceutical cocrystals: an emerging approach to physical property enhancement," MRS Bulletin, vol. 31, no. 11, pp. 875-879, 2006.

[20] T. Friščič and W. Jones, "Recent advances in understanding the mechanism of cocrystal formation via grinding," Crystal Growth \& Design, vol. 9, no. 3, pp. 1621-1637, 2009.

[21] S. Jung and I. W. Kim, "Effects of polymers on the cocrystallization of adefovir dipivoxil and suberic acid," Polymer-Korea, vol. 37, no. 5, pp. 663-668, 2013.

[22] E. A. Losev and E. V. Boldyreva, "The role of a liquid in dry cogrinding: a case study of the effect of water on mechanochemical 
synthesis in a L-serine-oxalic acid system," CrystEngComm, vol. 16, no. 19, pp. 3857-3866, 2014.

[23] J.-Y. Gal, J.-C. Bollinger, H. Tolosa, and N. Gache, "Calcium carbonate solubility: a reappraisal of scale formation and inhibition," Talanta, vol. 43, no. 9, pp. 1497-1509, 1996.

[24] K. K. Sand, J. D. Rodriguez-Blanco, E. Makovicky, L. G. Benning, and S. L. S. Stipp, "Crystallization of $\mathrm{CaCO}_{3}$ in wateralcohol mixtures: spherulitic growth, polymorph stabilization, and morphology change," Crystal Growth \& Design, vol. 12, no. 2, pp. 842-853, 2012.

[25] S.-W. Song, K. Hidajat, and S. Kawi, "pH-Controllable drug release using hydrogel encapsulated mesoporous silica," Chemical Communications, no. 42, pp. 4396-4398, 2007.

[26] C. Aguzzi, M. C. Bonferoni, M. R. Osorio Fortich, S. Rossi, F. Ferrari, and C. Caramella, "Influence of complex solubility on formulations based on lambda carrageenan and basic drugs," AAPS PharmSciTech, vol. 3, no. 3, pp. 83-89, 2002.

[27] H. Sun, "COMPASS: an ab initio force-field optimized for condensed-phase applications-overview with details on alkane and benzene compounds," Journal of Physical Chemistry B, vol. 102, no. 38, pp. 7338-7364, 1998.

[28] S. E. Wolf, N. Loges, B. Mathiasch et al., "Phase selection of calcium carbonate through the chirality of adsorbed amino acids," Angewandte Chemie International Edition, vol. 46, no. 29, pp. 5618-5623, 2007.

[29] C. Klein and C. S. Hurlbut Jr., Manual of Mineralogy, John Wiley \& Sons, New York, NY, UA, 21st edition, 1993.

[30] D. L. Graf, "Crystallographic tables for the rhombohedral carbonates," The American Mineralogist, vol. 46, no. 11-12, pp. 1283-1316, 1961.

[31] J. P. R. de Villiers, "Crystal structures of aragonite, strontianite, and witherite," The American Mineralogist, vol. 56, no. 5-6, pp. 758-767, 1971.

[32] S. Nosé, "A unified formulation of the constant temperature molecular dynamics methods," Journal of Chemical Physics, vol. 81, no. 1, pp. 511-519, 1984.

[33] N. Shankland, A. J. Florence, P. J. Cox et al., "Crystal morphology of ibuprofen predicted from single-crystal pulsed neutron diffraction data," Chemical Communications, no. 7, pp. 855-856, 1996.

[34] H. Cano, N. Gabas, and J. P. Canselier, "Experimental study on the ibuprofen crystal growth morphology in solution," Journal of Crystal Growth, vol. 224, no. 3-4, pp. 335-341, 2001.

[35] I. W. Kim, M. R. Darragh, C. Orme, and J. S. Evans, "Molecular "tuning" of crystal growth by nacre-associated polypeptides," Crystal Growth \& Design, vol. 6, no. 1, pp. 5-10, 2006.

[36] Joint Committee on Powder Diffraction Standards, Powder Diffraction File, Card No. 05-0586 (calcite), No. 41-1475 (aragonite), Swarthmore, Pa, USA, 2003.

[37] H. H. Adler and P. F. Kerr, "Infrared study of aragonite and calcite," The American Mineralogist, vol. 47, no. 5-6, pp. 700-717, 1962.

[38] J. A. Speer, "Crystal chemistry and phase relations of orthorhombic carbonates," in Carbonates: Mineralogy and Chemistry, R. J. Reeder, Ed., vol. 11, chapter 5, pp. 145-190, Mineralogical Society of America, Washington, DC, USA, 1983.

[39] I. W. Kim, R. E. Robertson, and R. Zand, "Selected polymorphs of $\mathrm{CaCO}_{3}$ through epitaxy with inorganic substrates aligned with an electric field," Advanced Materials, vol. 15, no. 9, pp. 709712,2003
[40] K. H. Stone, S. H. Lapidus, and P. W. Stephens, "Implementation and use of robust refinement in powder diffraction in the presence of impurities," Journal of Applied Crystallography, vol. 42, no. 3, pp. 385-391, 2009.

[41] B. D. Cullity and S. R. Stock, Elements of X-Ray Diffraction, Prentice Hall, Upper Saddle River, NJ, USA, 3rd edition, 2001.

[42] L. H. Sperling, "The Crystalline State," in Introduction to Physical Polymer Science, chapter 6, pp. 198-278, John Wiley \& Sons, New York, NY, USA, 2nd edition, 2008.

[43] J. Chung and I. W. Kim, "Effects of some polymeric additives on the cocrystallization of caffeine," Journal of Crystal Growth, vol. 335, no. 1, pp. 106-109, 2011. 

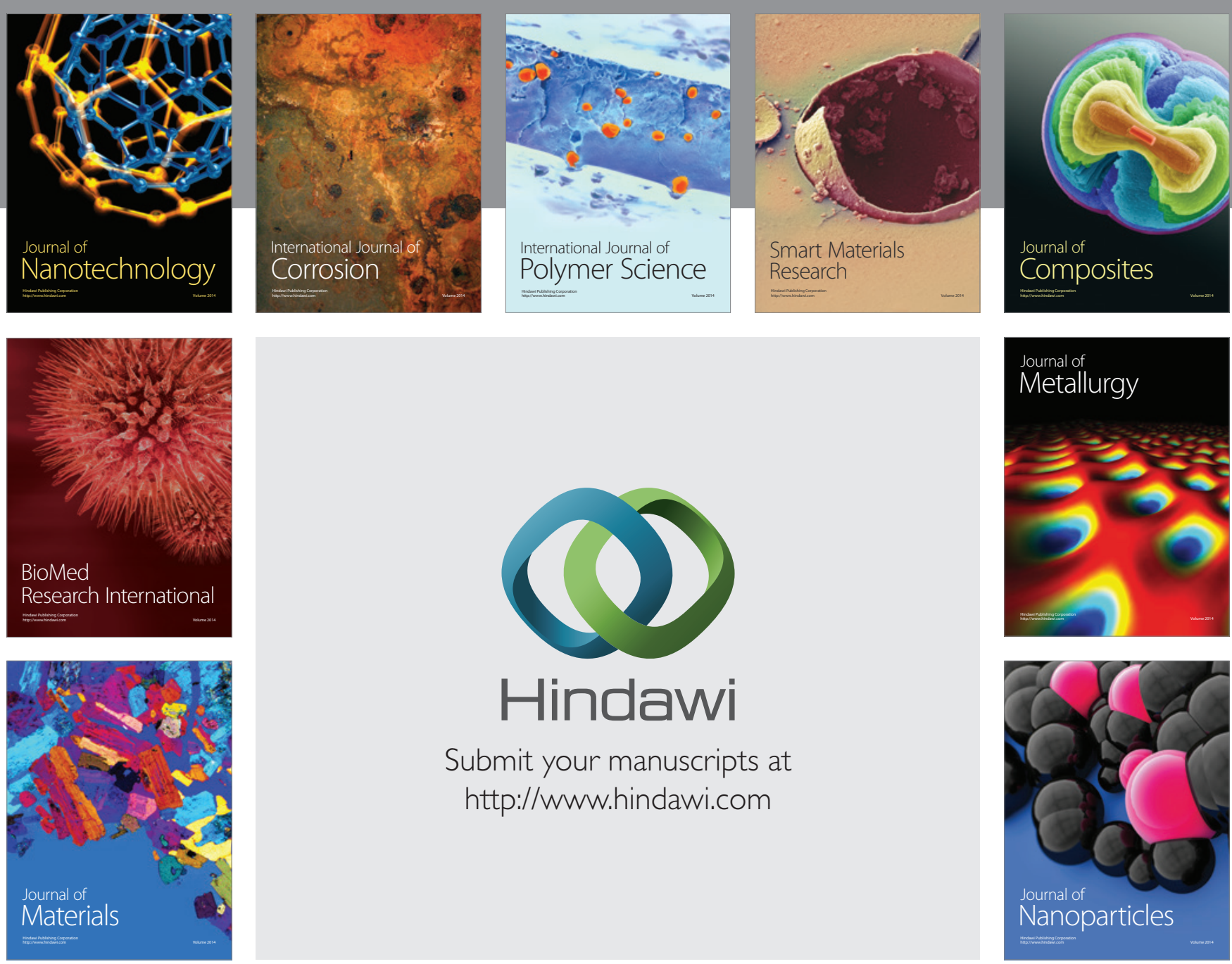

Submit your manuscripts at http://www.hindawi.com
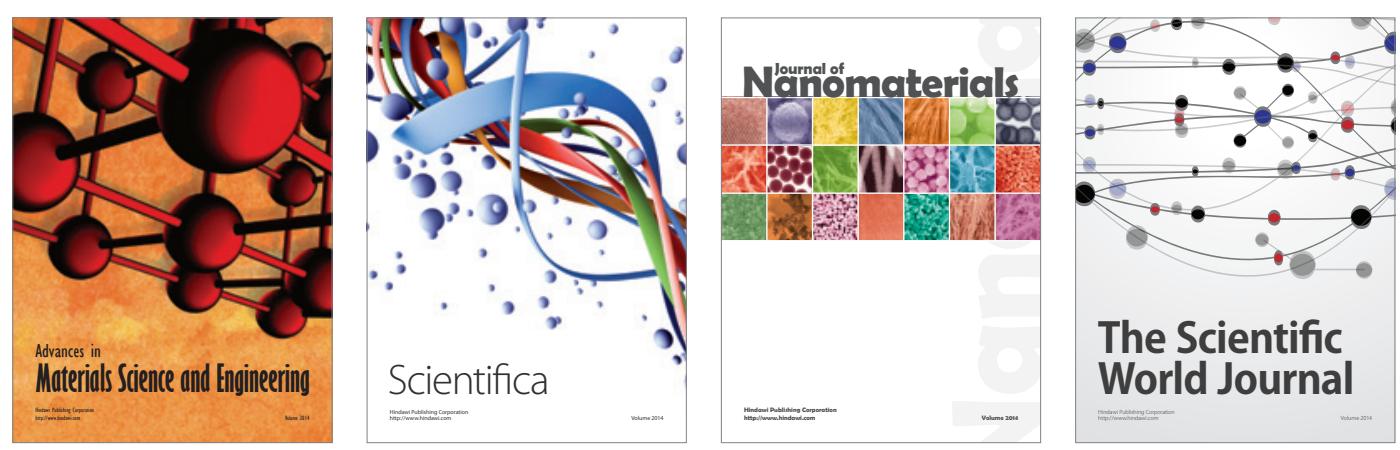

\section{The Scientific World Journal}
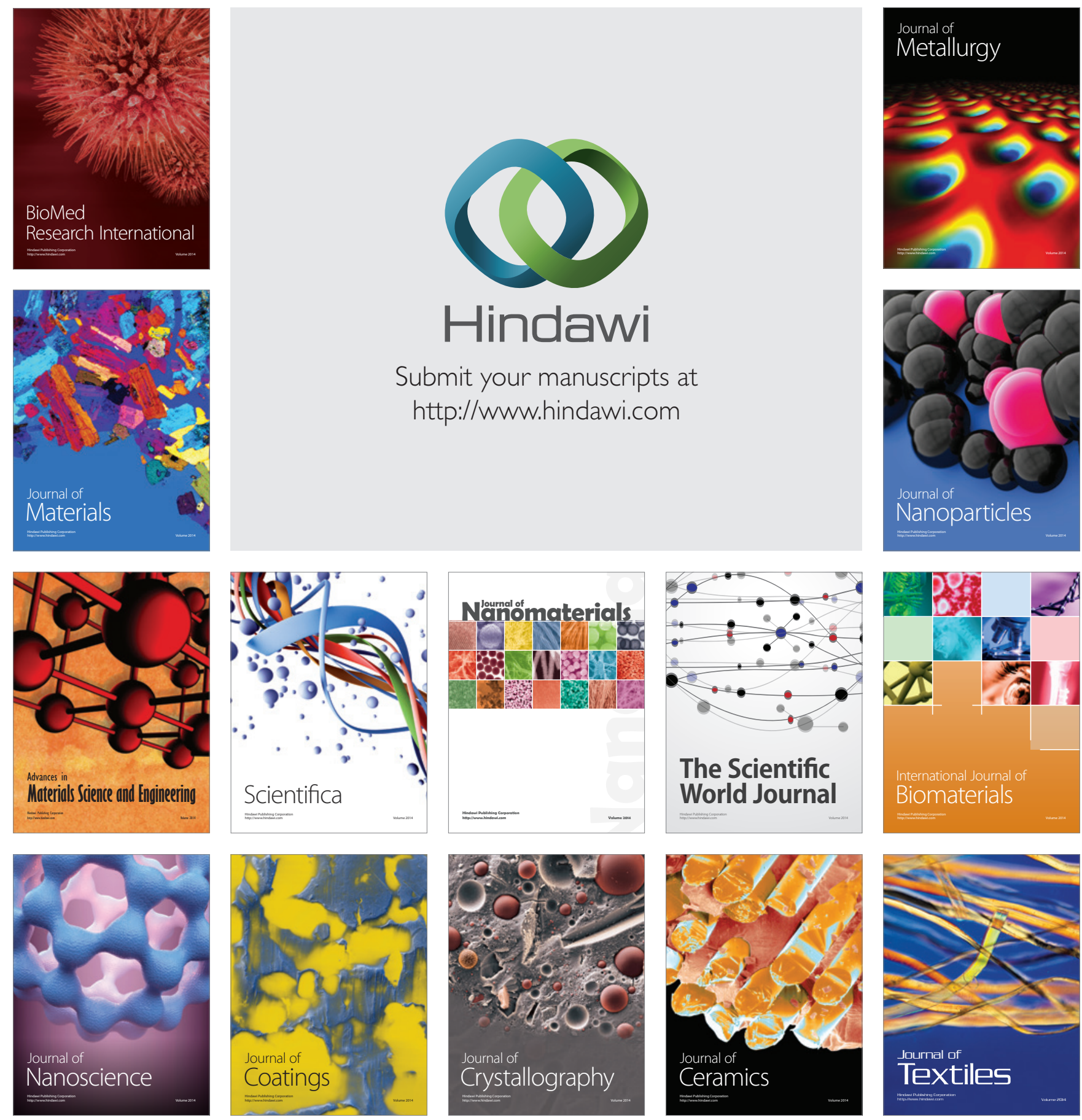